\title{
$\beta$-Cyclodextrin Inclusion Complex to Improve Physicochemical Properties of Pipemidic Acid: Characterization and Bioactivity Evaluation
}

\author{
Rosa Iacovino ${ }^{1}{ }^{*}$, Filomena Rapuano ${ }^{2}$, Jolanda Valentina Caso ${ }^{1}$, Agostino Russo ${ }^{1}$, \\ Margherita Lavorgna ${ }^{1}$, Chiara Russo ${ }^{1}$, Marina Isidori ${ }^{1}$, Luigi Russo ${ }^{1}$, Gaetano Malgieri ${ }^{1}$ and \\ Carla Isernia $^{1}$
}

1 Department of Environmental, Biological and Pharmaceutical Sciences and Technologies, Second University of Naples, Via A. Vivaldi 43, 81100 Caserta, Italy;

E-Mails: valentina.caso@unina2.it (J.V.C.); agostino.russo@unina2.it (A.R.); margherita.lavorgna@unina2.it (M.L.); chiara.russo@unina2.it (C.R.); marina.isidori@unina2.it (M.I.); luigi.russo2@unina2.it (L.R.); gaetano.malgieri@unina2.it (G.M.); carla.isernia@unina2.it (C.I.)

2 Department of Biological and Environmental Science, University of Sannio, Via Port'Arsa 11, 82100 Benevento, Italy; E-Mail: filomena.rapuano@unisannio.it

* Author to whom correspondence should be addressed; E-Mail: rosa.iacovino@ unina2.it; Tel.: +39-82-3274-663; Fax: +39-82-3274-605.

Received: 13 May 2013; in revised form: 8 June 2013 / Accepted: 13 June 2013 / Published: 25 June 2013

\begin{abstract}
The aptitude of cyclodextrins (CDs) to form host-guest complexes has prompted an increase in the development of new drug formulations. In this study, the inclusion complexes of pipemidic acid (HPPA), a therapeutic agent for urinary tract infections, with native $\beta$-CD were prepared in solid state by kneading method and confirmed by FT-IR and ${ }^{1} \mathrm{H}$ NMR. The inclusion complex formation was also characterized in aqueous solution at different $\mathrm{pH}$ via UV-Vis titration and phase solubility studies obtaining the stability constant. The 1:1 stoichiometry was established by a Job plot and the inclusion mechanism was clarified using docking experiments. Finally, the antibacterial activity of HPPA and its inclusion complex was tested on $P$. aeruginosa, E. coli and $S$. aureus to determine the respective $\mathrm{EC}_{50 \mathrm{~s}}$ and $\mathrm{EC}_{90 \mathrm{~s}}$. The results showed that the antibacterial activity of HPPA: $\beta-C D$ against $E$. coli and $S$. aureus is higher than that of HPPA. Furthermore, HPPA and HPPA: $\beta-C D$, tested on human hepatoblastoma HepG2 and MCF-7 cell lines by MTT assay, exhibited, for the first time, antitumor activities, and the complex revealed a higher
\end{abstract}


activity than that of HPPA. The use of $\beta$-CD allows an increase in the aqueous solubility of the drug, its bioavailability and then its bioactivity.

Keywords: $\beta$-cyclodextrin; pipemidic acid; inclusion complex; microbial activity; antitumoral activity

\section{Introduction}

Pipemidic acid (HPPA), 8-ethyl-5,8-dihydro-5-oxo-2-(1-piperazinyl)-pyrido[2,3-d]pyrimidine-6carboxylic acid [1,2] shown in Figure 1, is a therapeutic agent for urinary tract infections because of its antibacterial activity against gram-negative as well as some gram-positive bacteria $[3,4]$. In the HPPA molecule, a quinolone derivate, the carboxylic group at C6-position makes this compound acidic while the piperazine in position 2 includes an amine group, which is basic. For these reasons, in aqueous solution, 2-piperazinyl quinolone exists in three different species: acidic for $\mathrm{pH}$ values under $\mathrm{pKa}_{1}=5.4$, neutral for $\mathrm{pH}$ value closely to isoelectric point $(\mathrm{pH}=6.8)$ and alkaline for $\mathrm{pH}$ values higher $\mathrm{pKa}_{2}=8.2$ [5]. The existing equilibria for these types of quinolones are shown in Figure 2. The HPPA structure is important for its activity; in fact, it shows a better activity against Pseudomonas aeruginosa than piromidic and nalidixic acids, structurally related to it [6]. This drug severely damages DNA in the absence of an exogenous metabolizing system and it may act as a multidentate ligand to coordinate with metal ions [7,8]. However, its very low aqueous solubility $[9,10]$ can cause formulation problems and limit its therapeutic application.

Figure 1. Molecular structure of HPPA.

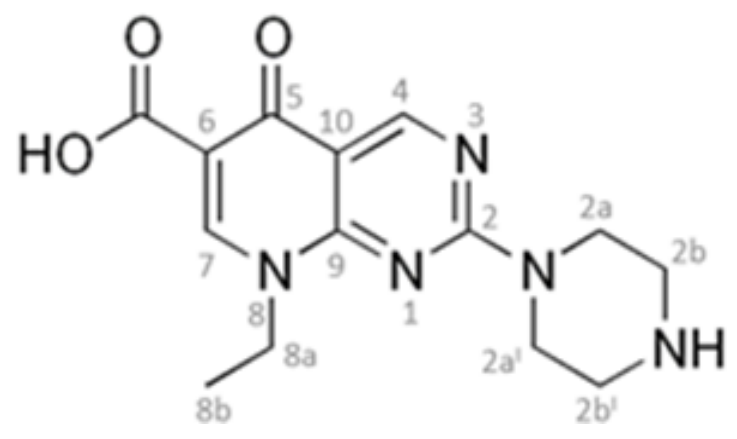

Figure 2. Acid-base equilibrium for piperazinyl quinolones, for $H P P A X=Y=N, R=H$ and $\mathrm{R}_{2}=\mathrm{CH}_{2} \mathrm{CH}_{3}$.

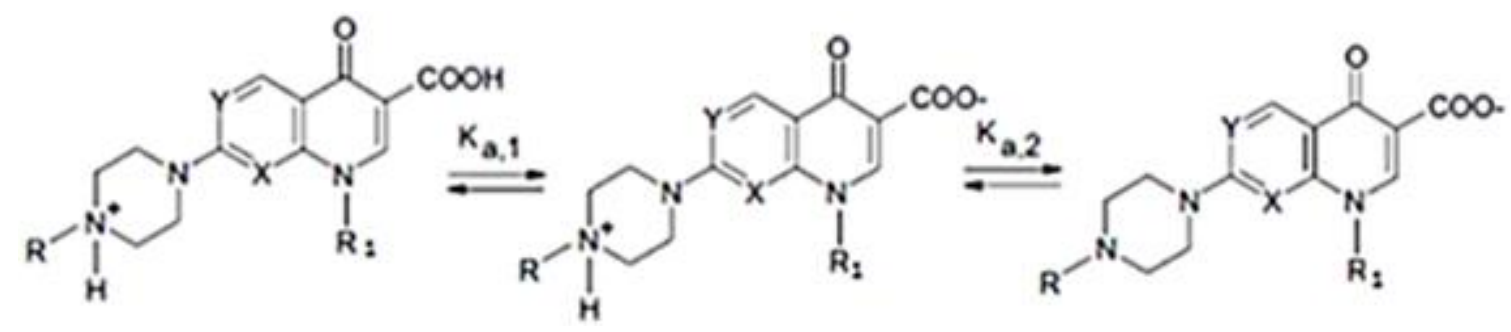


Cyclodextrins (CDs) are cyclic oligosaccharides which provide an interesting organic host system, since they have a hydrophobic inner cavity available to form non-covalent host-guest inclusion complexes with a wide variety of organic molecules of appropriate shape and size [11]. CDs are widely used to enhance the aqueous solubility of drugs [12-14] since the physicochemical properties of the guests (solubility, stability, bioavailability, antimicrobial activity, etc.) are altered upon complexation. For these reasons, in order to contribute to the increase of the HPPA aqueous solubility and thereby its pharmaceutical applications, we report here the preparation and characterization of inclusion complexes formed by HPPA with native $\beta$-CD. The inclusion complex HPPA: $\beta$-CD was prepared by kneading method and the adduct was characterized, in the solid state, by Fourier Transform-Infrared spectroscopy (FT-IR) and, in the solution state, by Nuclear Magnetic Resonance (NMR). The stoichiometry and the stability constants $(\mathrm{Kb})$ of the complex, obtained in solution, were determined using the phase solubility diagram (PSD) and Ultraviolet-Visible (UV-Vis) spectroscopy. The influence of the HPPA molecule protonation state on the complex stability was also investigated by estimating the sensitivity of the complex formation constant $(\mathrm{Kb})$ as a function of $\mathrm{pH}$. Furthermore, to characterize the structural details of the complex we carried out a molecular docking study. To evaluate possible differences in antimicrobial efficiency of HPPA compared to HPPA: $\beta$-CD complex, different bioactivity tests were performed. The antibacterial activity was tested both on gram-negative and gram-positive bacteria: Pseudomonas aeruginosa, Escherichia coli and Staphilococcus aureus. For each strain, the effective median inhibitory bacterial growth concentration $\left(\mathrm{EC}_{50}\right)$ as well as the respective $\mathrm{EC}_{90}$ were determined using the broth-based turbidimetric assay. Previous studies showed that some quinolones exhibited promising cytotoxicity in different human cancer cells $[15,16]$. For this reason the cytotoxicity of the investigated compounds were tested on human hepatoblastoma HepG2 and human breast cancer MCF-7 cell lines by MTT assay. The inclusion of HPPA with $\beta$-CD appears to modulate the capability of the parent compound to penetrate into the cells and improves the antitumor activity of HPPA against breast and hepatocellular cancers, suggesting attractive roles for applications in medicine.

\section{Results and Discussion}

\subsection{FT-IR Spectroscopy}

The FT-IR spectrum gives detailed information about the functional groups involved in the interaction when the complex is formed.

The spectra of $\beta-C D$, HPPA: $\beta-C D$ obtained by kneading techniques (KND), physical mixing product (PM) and HPPA are shown in Figure 3. The FT-IR spectrum of $\beta$-CD showed prominent absorption bands at $3392 \mathrm{~cm}^{-1}$ (for $\mathrm{O}-\mathrm{H}$ stretching vibrations), $2925 \mathrm{~cm}^{-1}$ (for $\mathrm{C}-\mathrm{H}$ stretching vibrations), $1158 \mathrm{~cm}^{-1}$ (for $\mathrm{C}-\mathrm{O}$ stretching vibrations), and $1028 \mathrm{~cm}^{-1}$ (C-O-C stretching vibrations), according to Menezes et al. [17]. In the FT-IR spectrum of HPPA, one prominent characteristic peak was found at $3046 \mathrm{~cm}^{-1}$, which was assigned to stretching vibration of the $-\mathrm{OH}$ group and intramolecular hydrogen bonding. This band also suggested how the $-\mathrm{NH}\left(3366 \mathrm{~cm}^{-1}\right)$ stretching vibration of the imino-moiety of piperazinyl groups was less prominent due to intense - $\mathrm{OH}$ stretching vibration. The band at $1721 \mathrm{~cm}^{-1}$ represented the carbonyl $\mathrm{C}=\mathrm{O}$ stretching. The peak at $1627 \mathrm{~cm}^{-1}$ was 
assigned to the $\mathrm{N}-\mathrm{H}$ bending vibration of quinolones [18]. The band at $1440 \mathrm{~cm}^{-1}$, representing $\mathrm{O}-\mathrm{C}-\mathrm{O}$ stretching vibration of acid, and that at $1261 \mathrm{~cm}^{-1}$ suggesting bending vibration of $\mathrm{O}-\mathrm{H}$ group, indicate the presence of carboxylic acid. The peak at $1354 \mathrm{~cm}^{-1}$ was assigned to the out-of-plane bending of the hydroxyl function of the carboxylic acid. The spectrum of the PM product shows approximate superimposition of the individual patterns of both $\beta-\mathrm{CD}$ and HPPA. In the spectrum of the $\mathrm{KND}$, the $-\mathrm{NH}$ stretching region of HPPA $\left(3366 \mathrm{~cm}^{-1}\right)$ is covered by the $\mathrm{O}-\mathrm{H}$ stretching band $\left(3392 \mathrm{~cm}^{-1}\right)$ of $\beta-C D$. The strong carboxyl carbonyl stretching vibration peak at $1721 \mathrm{~cm}^{-1}$ of HPPA disappears, the bending vibration of $\mathrm{O}-\mathrm{H}$ group of carboxylic acid at $1261 \mathrm{~cm}^{-1}$ of HPPA shifts to $1252 \mathrm{~cm}^{-1}$ with broadening in the complex, indicating the dissociation of the intermolecular hydrogen bonding and interaction through hydrogen bonding with $\beta-\mathrm{CD}$. The intensification and the shift of the peak at $1354 \mathrm{~cm}^{-1}$ of HPPA take place in the complex supporting the involvement of the carboxylic acid function in the complex formation. The intermolecular $\mathrm{C}-\mathrm{O}-\mathrm{C}$ stretch (ether linkage of $\beta-\mathrm{CD}$ ) at $1028 \mathrm{~cm}^{-1}$ is not affected indicating that the penetration of HPPA is through the axial line of the $\beta$-CD cavity [19].

Figure 3. FT-IR spectra of $\beta-C D, K N D$, PM and HPPA.

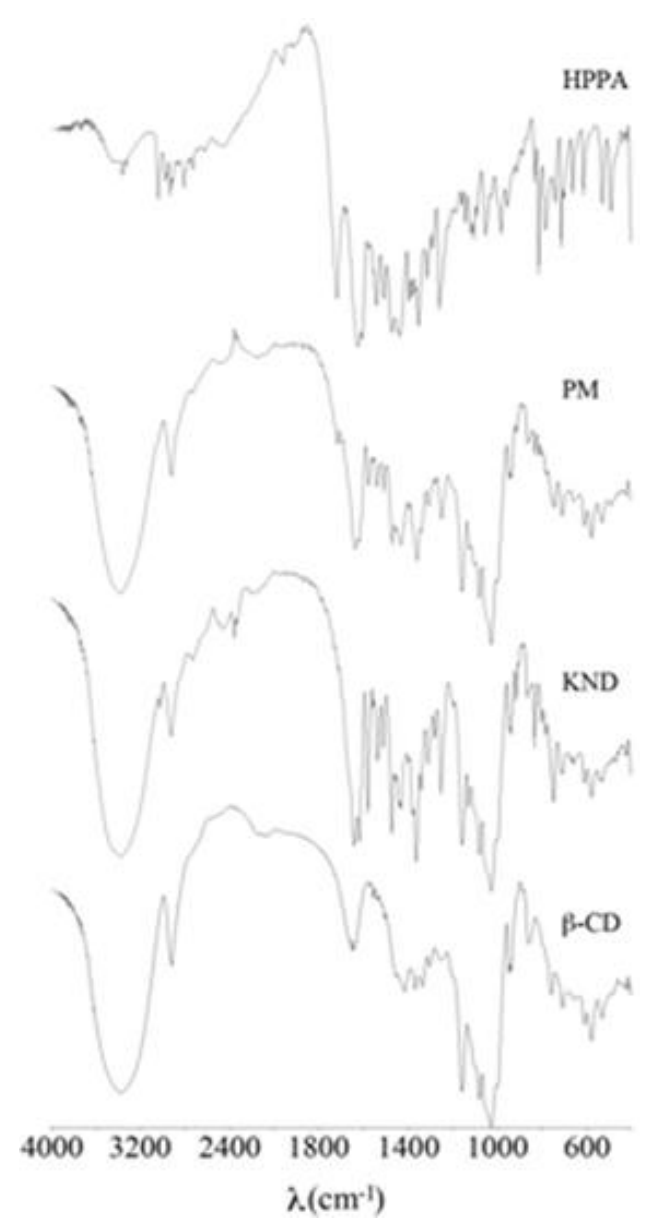

\subsection{NMR Spectroscopy}

The proton chemical shifts for free HPPA (Figure 1) are summarized in the experimental section. A strong NOE correlation of the proton in position 7 with the proton in position $8 \mathrm{a}$ and a weaker NOE 
between 7 and $8 \mathrm{~b}$ permitted a discrimination between proton in position 7 and 4 . The signals belonging to protons 2a-2a' and 2b-2b' were assigned based on the chemical shift reported by Jinxia Li et al. [20]. Figure 4 illustrates the ${ }^{1} \mathrm{H}$ NMR spectra of $\beta-C D$, HPPA and of the KND. The clear changes in the signal pattern for $\beta$-CD further confirm the formation of the inclusion complex. The $\beta-C D$ glucopyranosyl residues in the spectrum of the KND produce three distinct signals for the protons in position 1. Moreover, differences are also evident in the chemical shift of protons in position 3 and 5 localized within the cyclodextrin cavity. This behavior clearly demonstrates the formation of an inclusion complex: the aromatic nature of the guest explains the differences in the magnetic field experienced by the same protons located on different unities. Moreover, changes in the chemical shifts of the HPPA protons in position 4, 7 and 8 (Figure 1) likely indicate that the aromatic part of the molecule is included in the $\beta$-CD cavity while the part containing protons in position 2 (the piperazinyl group), whose chemical shift remains almost unperturbed, is likely to be located outside the cavity. This behavior is further confirmed by the ROESY spectrum (Figure 5) in which two unambiguous NOEs prove the proximity of the methyl group of HPPA to the $\beta$-CD proton in position 5 and of protons $2 \mathrm{~b}$ and $2 \mathrm{~b}^{\prime}$ of the piperazinyl group to the $\beta$-CD proton in position 2 . These data have been confirmed by docking studies (see section 2.3 and Figure 6).

Figure 4. The ${ }^{1} \mathrm{H}$ NMR spectra of HPPA: $\beta-C D$ kneading product $(\mathbf{A}), \beta-\mathrm{CD}(\mathbf{B})$ and HPPA $(\mathbf{C})$.
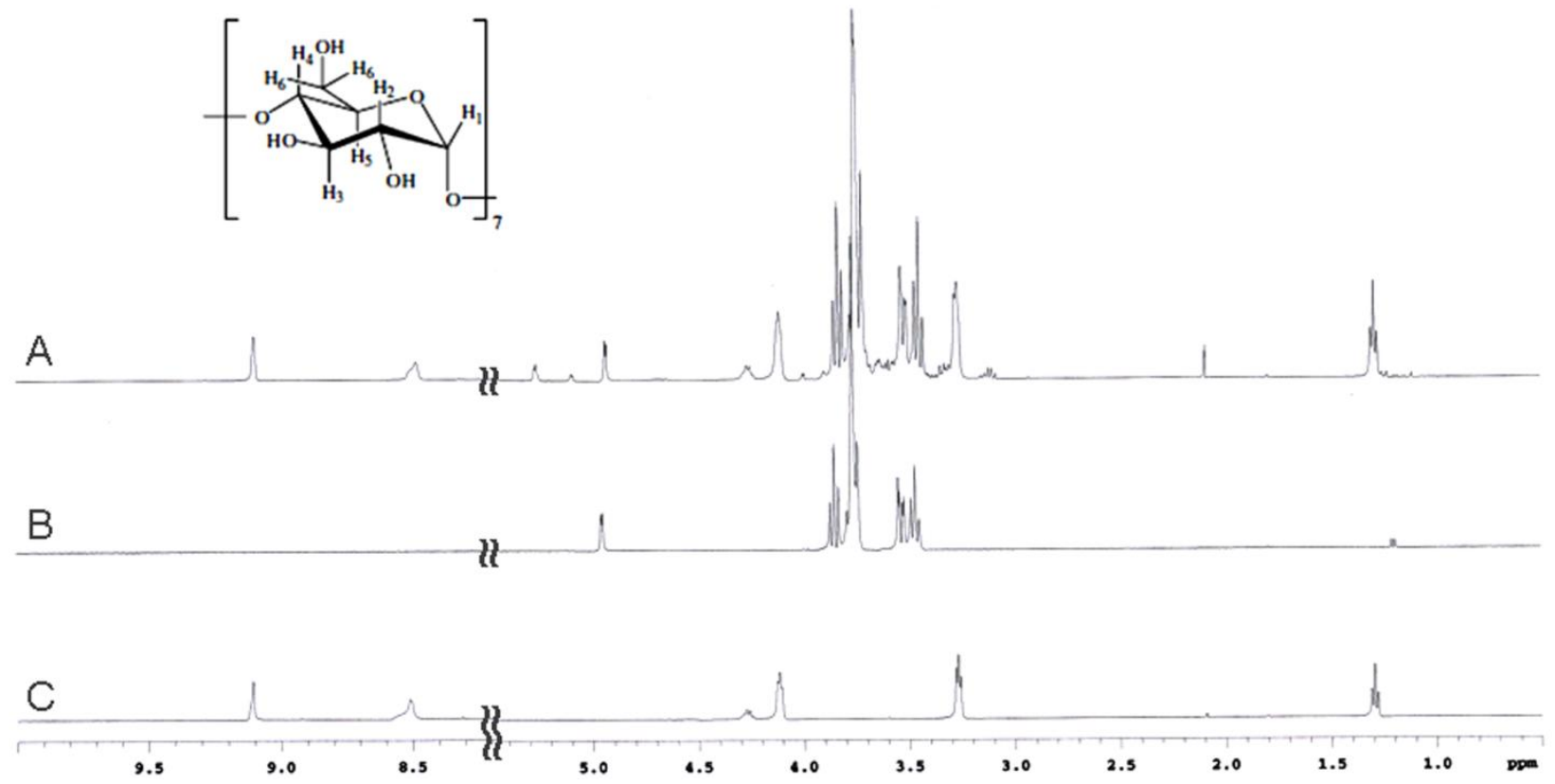
Figure 5. Region of the ${ }^{1} \mathrm{H}-{ }^{1} \mathrm{H}$ ROESY spectrum of the KND product with the negative cross peaks marked with a dotted line.

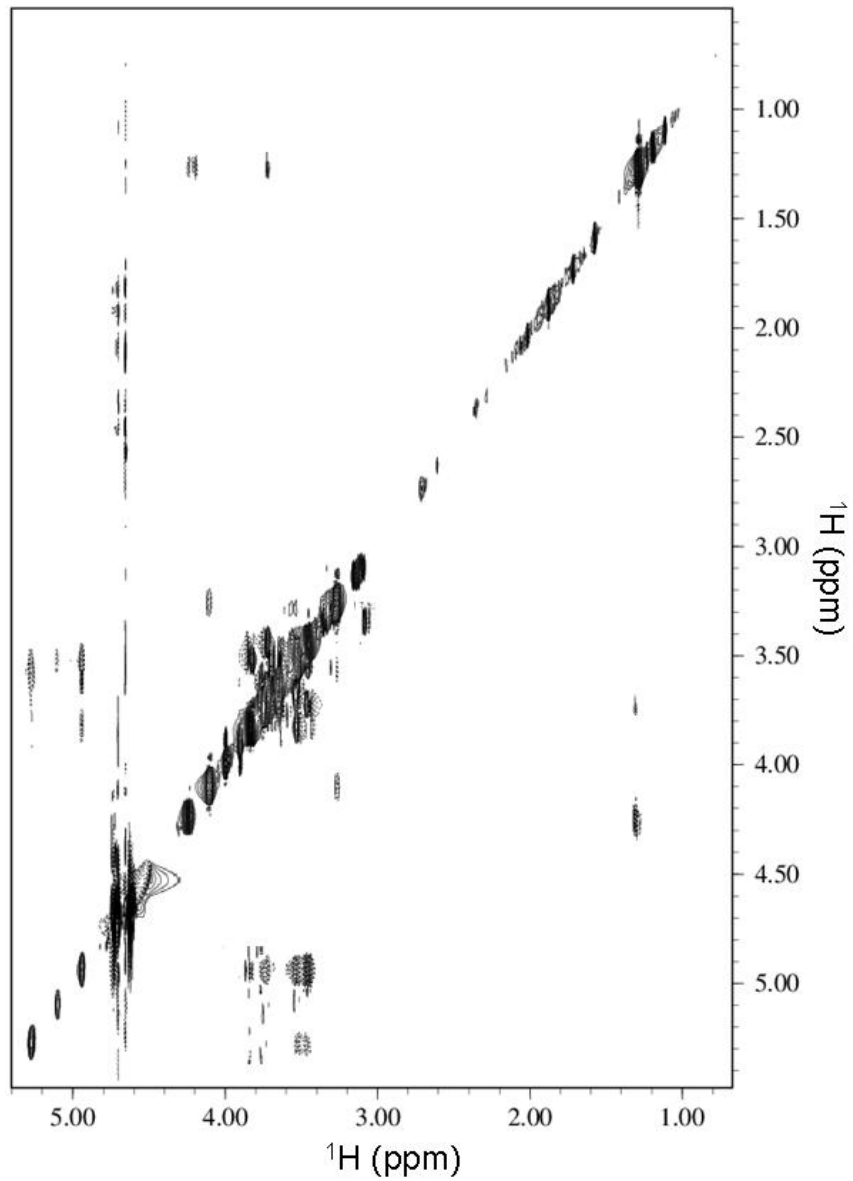

Figure 6. Optimized structure of $\beta-\mathrm{CD}$ in complex with HPPA.

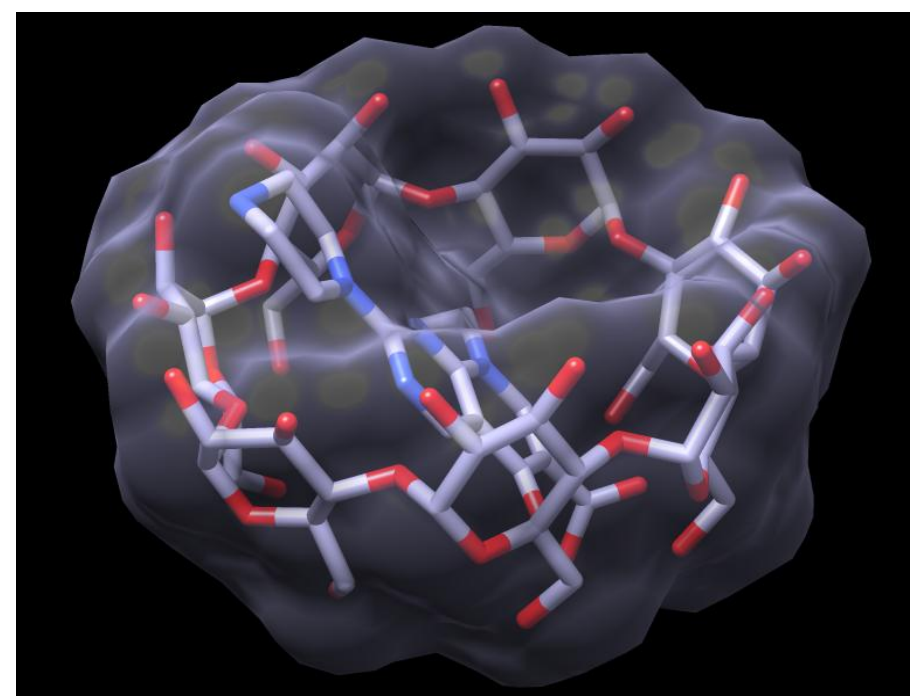

\subsection{Docking of HPPA onto $\beta-C D$}

For a deeper understanding of the molecular encapsulation capacity of $\beta-C D$, a docking study was performed. The optimized structure of the HPPA: $\beta$-CD complex is reported in Figure 6 . The results show that the amino ring of HPPA is located inside the hydrophobic cavity of the $\beta$-CD. Moreover, in 
accord with the NMR data, the structure of the complex indicates that the less polar part of the molecule is inserted into the cavity, while the more polar groups are exposed to the bulk solvent outside the opening of the cavity.

\subsection{UV-Vis Spectroscopy}

The modification in UV-Vis spectrum of the guest molecule is assumed to result from changes in its solvent microenvironment upon inclusion [21]. The stoichiometry of the complex was determined using Job method [22,23]. The 1:1 stoichiometry is given by the curve maximum at $R=0.5$ (Figure 7). The evaluation of stability constants by direct spectroscopic methods relies on analytical differences between the free and complexed drug [24]. The HPPA can be present in different cationic, zwitterionic or anionic forms depending on the $\mathrm{pH}$ of the solution and each of them may form complexes with the $\beta-\mathrm{CD}$. Thus, the inclusion of HPPA with $\beta-\mathrm{CD}$ was studied in unbuffered $(\mathrm{pH}=6.8)$, sodium acetate buffered $(\mathrm{pH}=4.6)$ and Tris $\mathrm{HCl}$ buffered $(\mathrm{pH}=8.6)$ solutions. The results of the dependence of HPPA absorbance on $\beta$-CD concentration are shown in Figure 8. The maximum absorption wavelength of HPPA was $\mathrm{pH}$ dependent, being $323.0 \mathrm{~nm}$ at $\mathrm{pH} 4.6,330.0 \mathrm{~nm}$ at $\mathrm{pH} 6.8$, and $331.5 \mathrm{~nm}$ at $\mathrm{pH}$ 8.6. These results suggest that the inclusion complex was formed between $\beta$-CD and HPPA. The $K_{\mathrm{b}}$ can be obtained from absorbance data using the modified Benesi-Hildebrand [25,26] Equation (1):

$$
A=-\frac{1}{K_{\mathrm{b}}} \frac{A-A_{0}}{[H]}+A_{0}+\Delta \varepsilon[G]
$$

where $A$ and $A_{0}$ are the absorbance of HPPA in the presence and absence of $\beta-\mathrm{CD}$, respectively, $K_{\mathrm{b}}$ is the stability constant, $[H]$ and $[G]$ are the concentrations of $\beta$-CD and HPPA, respectively and $\Delta \varepsilon$ is the difference in the molar absorptivities between free and complexed guest. Therefore, a plot of A versus $\left(A-A_{0}\right) /[H]$, should give a straight line with slope $-1 / K_{\mathrm{b}}$. The calculated stability constants at different $\mathrm{pH}$ were listed in Table 1 , from which the formation constant values were very sensitive to $\mathrm{pH}$ : $K_{\mathrm{b} 4.8}>K_{\mathrm{b} 6.8} \approx K_{\mathrm{b} 8.6}$. Thus, it can be concluded that the inclusion of HPPA molecule with $\beta$-CD is more suitable in acidic media. The negatively charged HPPA with more hydrophilic character was predominant in basic media, or in aqueous solution, leading to the weaker interaction with $\beta-\mathrm{CD}$.

Figure 7. Job plot for the complex HPPA: $\beta-\mathrm{CD}(\lambda=330.0 \mathrm{~nm})$.

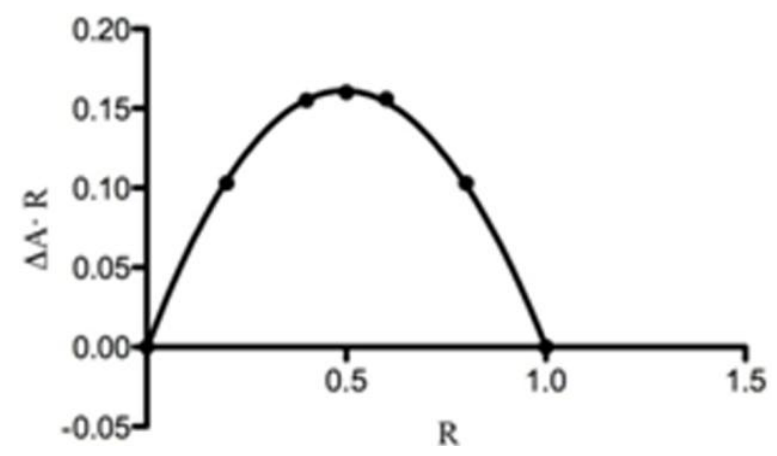


Figure 8. Dependence of HPPA absorbance from $\beta$-CD concentration in aqueous solutions with different $\mathrm{pH}$ values: (a) $\mathrm{pH}=4.6(\lambda=323.0)$; (b) $\mathrm{pH}=6.8(\lambda=330.0)$; (c) $\mathrm{pH}=8.6$ $(\lambda=331.5)$.
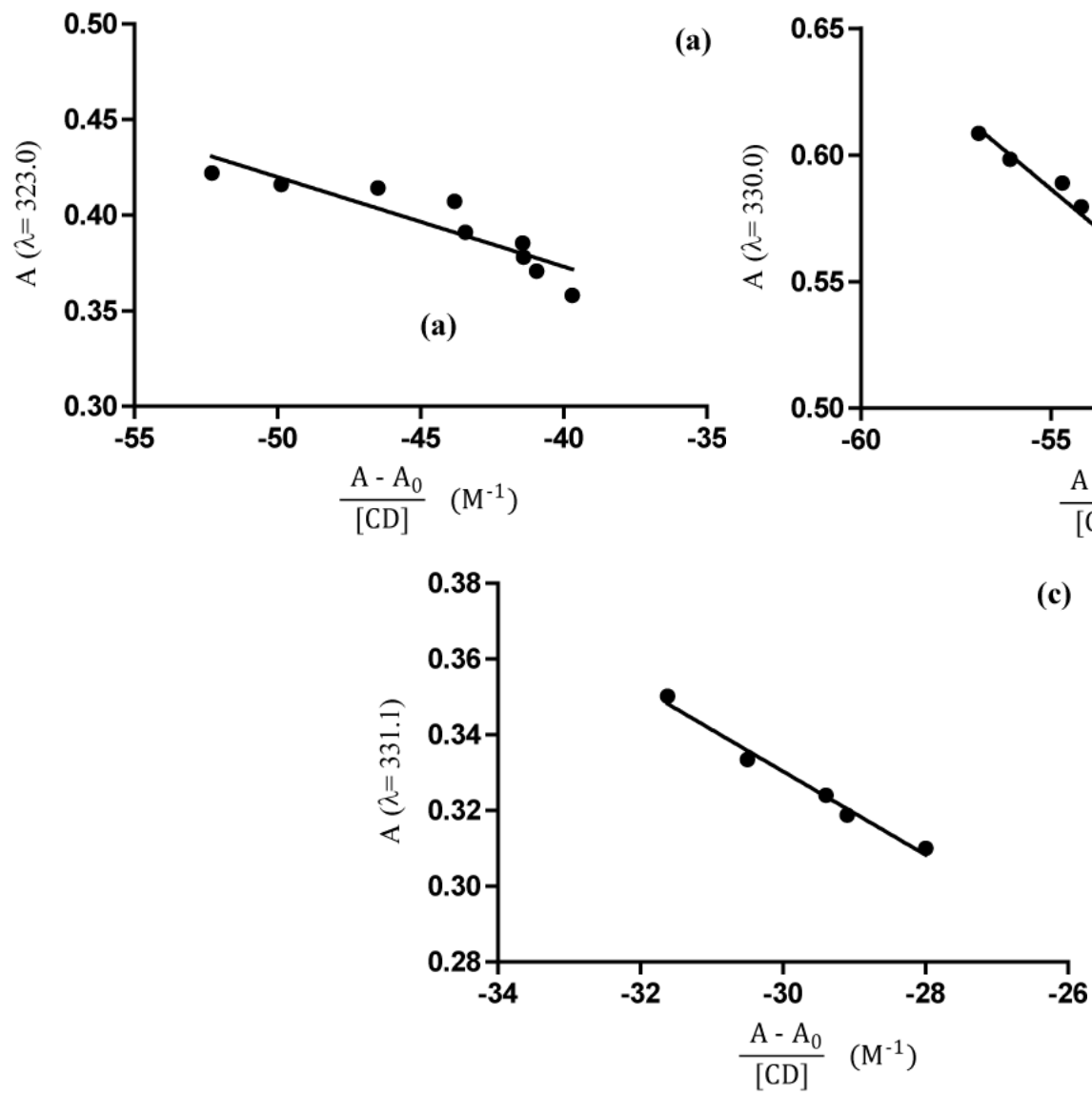

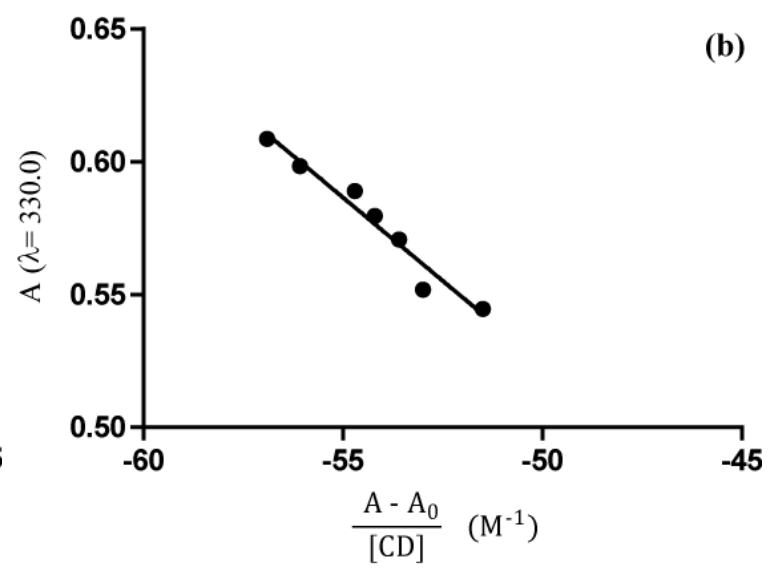

(c)

Table 1. The stability constants of $\beta-\mathrm{CD}$ with HPPA were calculated by absorbance measurement in different $\mathrm{pH}$ values.

\begin{tabular}{ccc}
\hline $\mathbf{p H}$ & $\boldsymbol{K}_{\mathbf{b}}\left(\mathbf{M}^{-\mathbf{1}}\right) \mathbf{U V}-\mathbf{V i s}$ & $\boldsymbol{K}_{\mathbf{b}}\left(\mathbf{M}^{\mathbf{- 1}}\right) \mathbf{P S D}$ \\
\hline 4.6 & 215.2 & 250.8 \\
6.8 & 79.7 & 88.5 \\
8.6 & 90.8 & 86.7 \\
\hline
\end{tabular}

Phase Solubility Studies

To estimate the stoichiometric ratios and stability constant of the HPPA: $\beta-C D$ in solution we carried out phase solubility studies measuring the change of solubility of the guest substance as a function of the host concentration. The PSDs for the formation of complexes between HPPA and $\beta-C D$ at different $\mathrm{pH}$ values are shown in Figure 9. The PSD obtained for the HPPA acid form $(\mathrm{pH}=4.6)$ can be classified as Bs type according to Higuchi and Connors [27]. In this case, the HPPA solubility is enhanced by the presence of the host; in particular, a linear increase of solubility for HPPA was observed up to $3 \times 10^{-3} \mathrm{M}$ of $\beta-\mathrm{CD}$. The ascending portion of the Bs type curve indicates that the stoichiometry of the complex is $1: 1$; then a short plateau region indicates the formation of an insoluble, or with different stoichiometry, complex in the solution at high concentrations of $\beta$-CD. Rigorous 
nonlinear regression [28] of experimental data was conducted to obtain estimates of stability constant. Data analysis and nonlinear regression curve fitting were performed using Prism 5 software (GraphPad, San Diego, CA, USA). The value of $\mathrm{Kb}$ was found to be $250.8 \mathrm{M}^{-1}$, according to the value obtained by UV-Vis method. The PSD for HPPA: $\beta-C D$ in buffered solutions at $\mathrm{pH}=8.6$ and in unbuffered solution $(\mathrm{pH}=6.8$ ), shows that the aqueous solubility of the drug increases linearly as a function of $\beta-C D$ concentration. The PSD can be classified as the $A_{L}$ type in both solutions and it indicates that the stoichiometry of the complex is $1: 1 . K_{\mathrm{b}}$ values were estimated according to the Equation (2) where $S_{0}$, HPPA concentration in the absence of $\beta-C D$, was obtained as the $y$-intercept.

$$
K_{\mathrm{b}}=\frac{\text { Slope }}{S_{0}(1-\text { Slope })}
$$

Figure 9. The PSD for the inclusion complex HPPA: $\beta-C D$ in aqueous solutions with different $\mathrm{pH}$ values: (a) $\mathrm{pH}=4.6$; (b) $\mathrm{pH}=6.8$; (c) $\mathrm{pH}=8.6$.
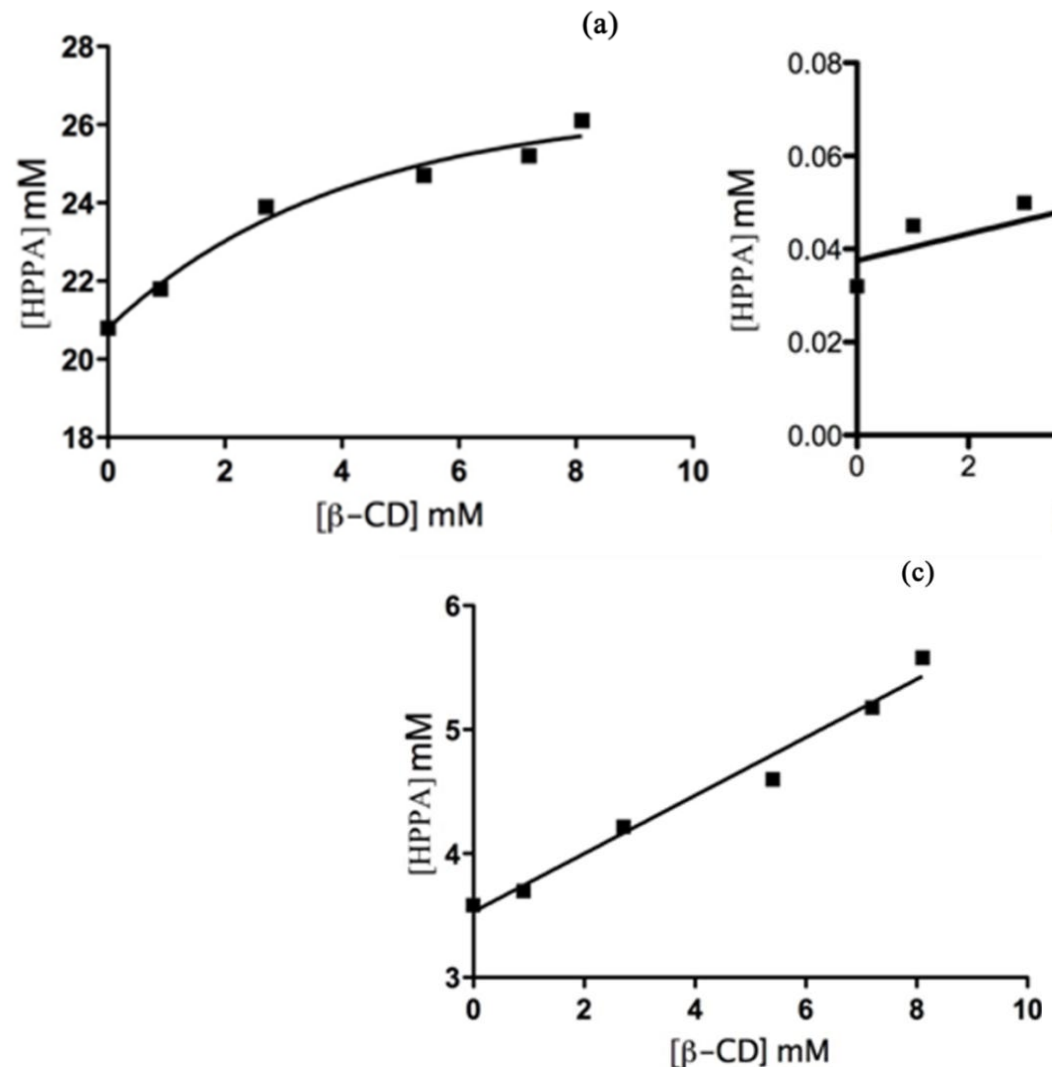

(b)

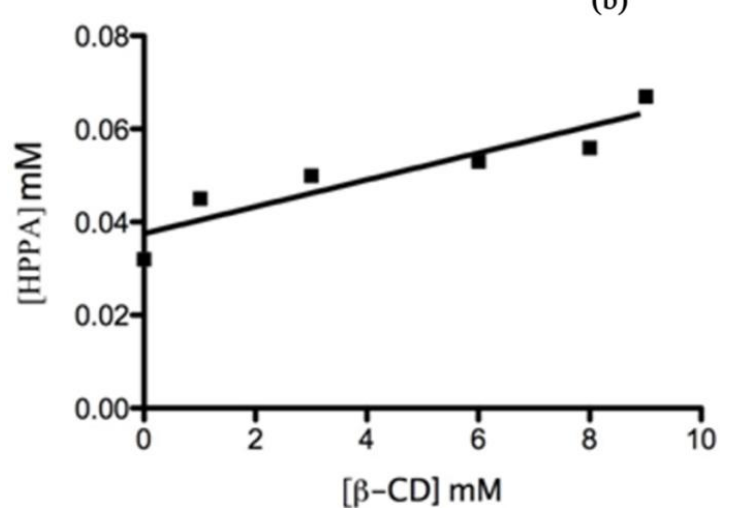

(c)

The binding constants (Table 1) were estimated to be equal to $88.5 \mathrm{M}^{-1}$ at $\mathrm{pH}=6.8$ and $87.0 \mathrm{M}^{-1}$ at $\mathrm{pH}=8.6$; these $K_{\mathrm{b}}$ values are in agreement with those obtained by UV-Vis. The stability constants obtained for HPPA: $\beta$-CD fall in the ideal range between 100 and $1000 \mathrm{M}^{-1}$ : smaller values indicated weak interactions between guest and $\beta-\mathrm{CD}$, while a large value indicates incomplete guest release from the inclusion complex [29]. If the complex is too weak, there is a slight improvement of the water solubility of the host. Moreover, if the complex is too strong, as shown through a stability constant greater than $1000 \mathrm{M}^{-1}$, the complex cannot dissociate easily. In this context, the bioavailability of HPPA is improved by complexation with $\beta$-CD. For this reason we have performed a number of bioactivity tests. The complex formation between HPPA and $\gamma$-CD was reported by 
Duran-Meras et al. [30] and the values of stability constants obtained by spectrofluorimetric methods resulted in very small values compared to the values obtained for the HPPA: $\beta-C D$, probably due to the different size of the $\gamma$-CD cavity.

\subsection{Bioactivity Evaluation}

\subsubsection{Microbial Susceptibility Test}

The antibacterial activities of the pure drug and its complex were tested against two Gram (-), E. coli and P. aeruginosa, and one Gram (+), S. aureus. The effective concentrations inhibiting 50\% of bacterial growth $\left(\mathrm{EC}_{50 \mathrm{~s}}\right)$ were determined and results are reported in Figure 10. According to the graph, pipemidic acid appeared to be most effective on $P$. aeruginosa with an $\mathrm{EC}_{50}$ value of $0.05 \mathrm{mM}$. A lower effect was found on $S$. aureus followed by $E$. coli with statistically significant differences in their activity for $p<0.05$. Furthermore, the efficiency of the complex was tested and results showed a significantly higher antibacterial potential of HPPA: $\beta-C D$ when compared to HPPA in E. coli $(p<0.01)$ and $S$. aureus $(p<0.05)$ by Tukey test. Probably the complex, enhancing HPPA transport through membranes, can improve inhibiting DNA replication HPPA efficacy in E. coli and $S$. aureus. Further experiments are needed in order to clarify the possible mechanism of action of HPPA: $\beta-C D$ in $P$. aeruginosa where the complex activity was lower than that shown by pure compound. In addition to the determination of $\mathrm{EC}_{50}$ values, $\mathrm{EC}_{90}$ values were also determined. $\mathrm{EC}_{90}$ represents the concentration able to generate $90 \%$ of bacterial growth inhibition, and it could be preferred to the Minimal Inhibitory Concentration (MIC) even if that is the most frequently used measure to detect the antibacterial activity. MIC, defined as the lowest concentration of the antimicrobial agent that prevents visible growth of a microorganism, is strongly influenced by the experimental conditions to obtain accurate and reproducible results as it is visually determined and based on operator decisions for the chosen concentrations and their spacing. The $\mathrm{EC}_{90}$ is an accurate measure because it represents the statistically determined concentration of the antimicrobial agent achieving $90 \%$ of growth inhibition compared to the control (without compounds). Results of the growth curves showing $\mathrm{EC}_{90}$ inhibition are reported in Figure 11. HPPA: $\beta-\mathrm{CD}$ showed the lowest $\mathrm{EC}_{90}$ equal to $0.45 \mathrm{mM}$ against $1.54 \mathrm{mM}$ of $\mathrm{HPPA}$ in $P$. aeruginosa. It is interesting to note that the complex improved the efficacy of the HPPA also in $S$. aureus and $E$. coli with $\mathrm{EC}_{90}$ values of 4.26 and $4.4 \mathrm{mM}$, respectively. HPPA showed $\mathrm{EC}_{90}$ values equal to 75.7 for E. coli and $63.01 \mathrm{mM}$ for $S$. aureus; this means that a lower HPPA amount in the complex (15-fold for $S$. aureus and 17-fold for E. coli) would be requested. All concentration/response curves followed the same trend with an increase in inhibition of HPPA: $\beta$-CD compared to HPPA at increasing concentrations. These findings could be of great interest in urinary tract infection therapy as HPPA is used, against E. coli and P. aeruginosa, in these types of infections [31-33]. The inclusion complex of HPPA with $\beta$-CD would allow lower doses of HPPA in therapy and consequently, lower adverse effects. HPPA has been extensively studied for its antibacterial potential especially using the MIC value determination, but results vary widely because of different test conditions and of non-standardized procedures. Our results partially agree with Yang et al. [34] who reported high inhibitory action against $E$. coli, slight inhibition against $P$. aeruginosa but no sensitivity on $S$. aureus. 
On the other hand, Efthimiadou et al. [8] found the highest antibacterial activity for HPPA on S. aureus. No studies were found using antibacterial assays on HPPA included into $\beta$-CD.

Figure 10. $\mathrm{EC}_{50}$ values calculated from the bacterial inhibition percentages for $E$. coli, $P$. aeruginosa and $S$. aureus co-incubated with HPPA and HPPA: $\beta$-CD. Error bars show standard deviation.

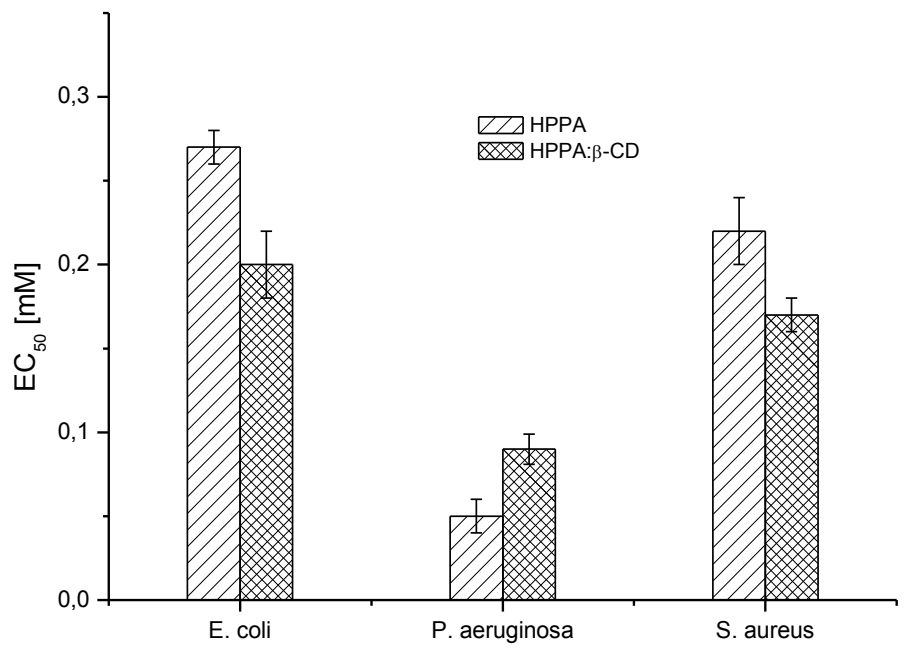

Figure 11. Concentration/response curves of HPPA and HPPA: $\beta-\mathrm{CD}$ showing the $\mathrm{EC}_{90}$ values against (a) E. coli, (b) P. aeruginosa and (c) S. aureus.

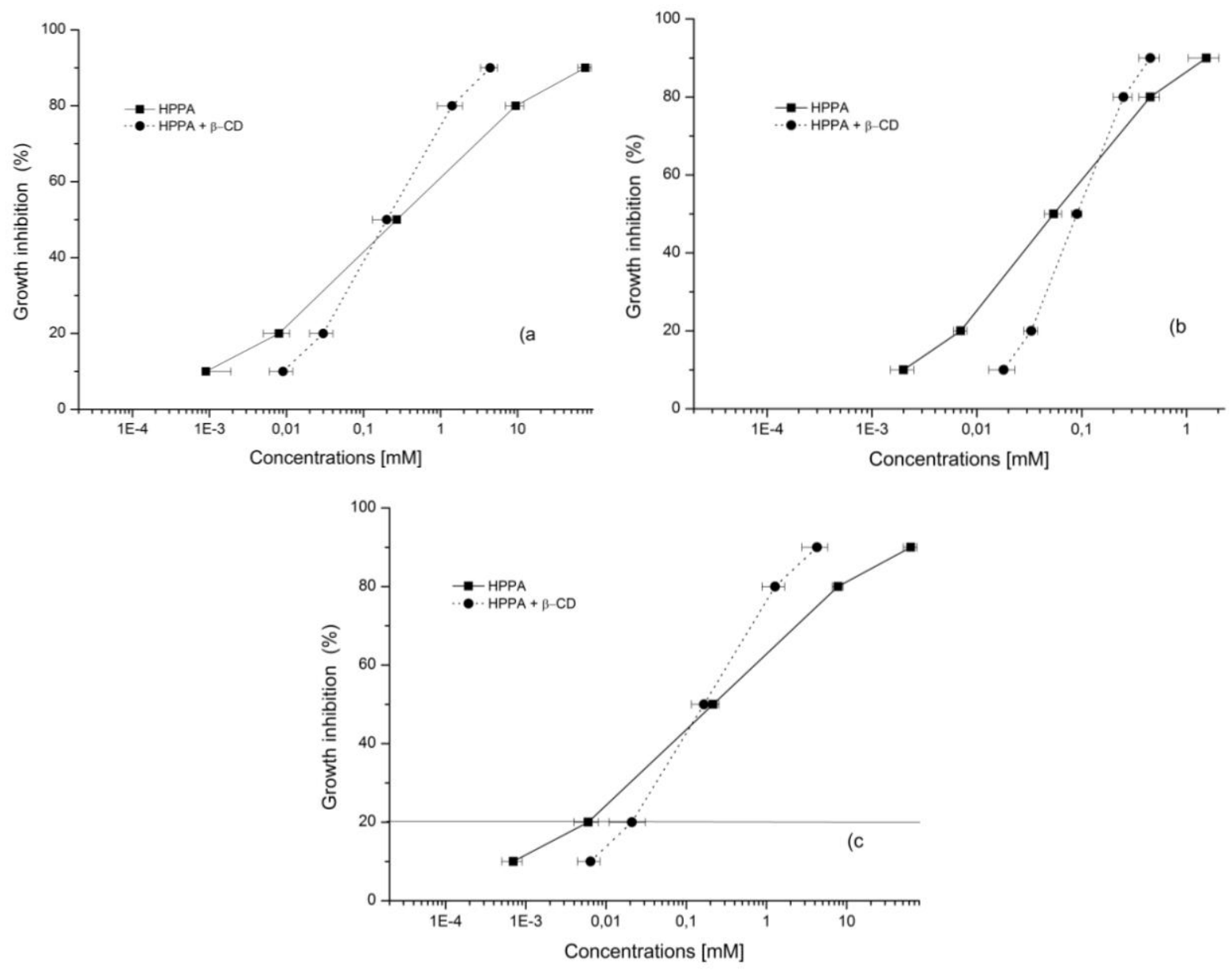




\subsubsection{MTT Assay}

MTT assays determine the citotoxicity of compounds considering the number of viable cells. In this study, human hepatocellular carcinoma (HepG2) and human breast adenocarcinoma (MCF-7) cell lines were used to detect possible differences in antitumor activity between HPPA and its complex with $\beta$-CD. The results are reported in Figure 12 where $\mathrm{IC}_{50}$ values are plotted against different incubation times. Our findings show that HPPA has a higher antitumor activity, around one order of magnitude, against hepatocellular carcinoma cells compared to breast cancer cells. The highest efficacy was shown at $72 \mathrm{~h}$ both for MCF-7 and HepG2. It is worth to underline that significant differences $(p<0.01)$ were found between $\mathrm{IC}_{50}$ values only at 24 and $48 \mathrm{~h}$ for HepG2 while $\mathrm{IC}_{50 \text { s }}$ for MCF-7 were statistically different for $p<0.01$ both at 24 and $48 \mathrm{~h}$, and 24 and $72 \mathrm{~h}$; a significativity of 0.05 was found between 48 and $72 \mathrm{~h}$. The efficiencies of HPPA: $\beta-C D$ compared to the pure compound evidenced that the inhibition of proliferation in MCF-7 cells was remarkable with $\mathrm{IC}_{50}$ values decreasing from 0.88 to $0.15 \mathrm{mM}$. The activity of the complex on the HepG2 was lower but, in any case, HPPA: $\beta$-CD showed an $\mathrm{IC}_{50}$ value more than half the value found for HPPA alone $(0.14$ versus $0.3 \mathrm{mM}$ ). At each time test the comparison between the complex and the pure compound showed significant differences for $p<0.01$. Both for MCF-7 and HepG2, the differences in activity can be reasonably explained by the modified chemistry of the complex. In fact, the inclusion of pipemidic acid into $\beta-C D$ can increase the transport of HPPA through the cellular membranes improving its cytotoxic activity. The quinolone investigated has been previously studied for its antitumor activity by other researchers who found changes in its potential when in complex with polyoxometallates (POMs) whose application in medicine is difficult for their low hydrolytic stability and low selectivity as well as high toxicity $[35,36]$. In the present study, the use of cyclodextrin allows the formation of a safe complex that increases the aqueous solubility of the drug, its bioavailability and then its antitumor activity.

Figure 12. Antitumor activity expressed as $\mathrm{IC}_{50}(\mathrm{mM})$ against MCF-7 and HepG2 cells of HPPA and HPPA: $\beta-C D$ after 24, 48 and $72 \mathrm{~h}$ of co-incubation.

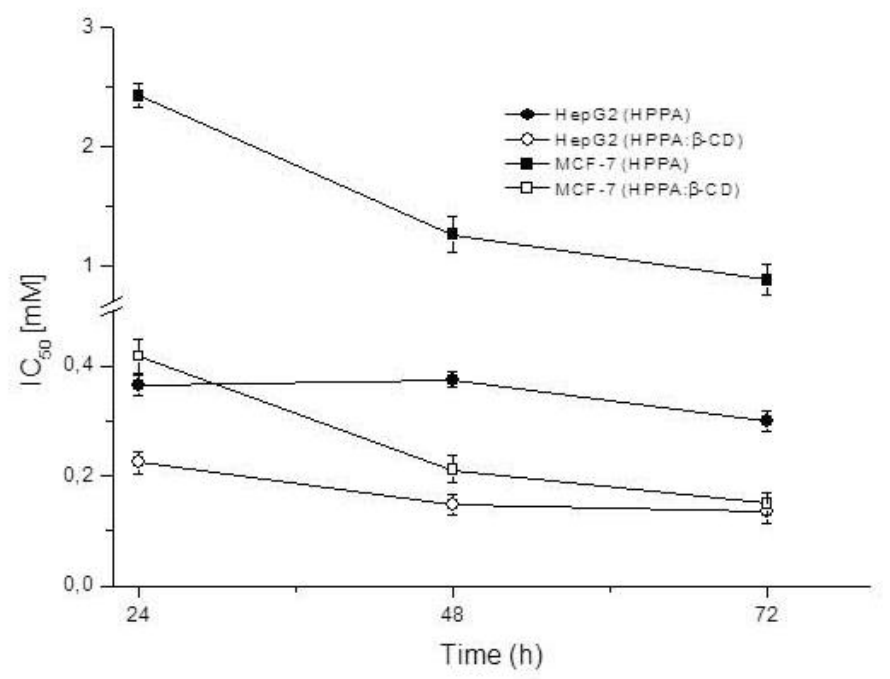




\section{Experimental Section}

\subsection{Materials}

$\beta-\mathrm{CD}$ and HPPA were purchased from Sigma-Aldrich. The buffer solutions at different pHs were prepared by adding the appropriate amounts of sodium acetate and Tris $\mathrm{HCl}$; the solutions were prepared just before taking each measurement. All the reagents and solvents were of analytical grade. Double distilled and MilliQ water was used throughout the experiments.

\subsection{Preparation of Solid Binary System}

The HPPA: $\beta-C D$ solid binary system was prepared in 1:1 molar ratio by following different methods.

\subsubsection{Physical Mixing Method}

The Physical Mixing product (PM) was prepared by simply blending powders of $\beta$-CD (0.100 g) and HPPA $(0.027 \mathrm{~g})$ in a mortar for $5 \mathrm{~min}$, at room temperature.

\subsubsection{Kneading Method}

Kneading product (KND) was obtained by adding a small volume of a water-methanol $(50 / 50, v / v)$ solution to the HPPA $(0.040 \mathrm{~g})$ and $\beta$-CD $(0.150 \mathrm{~g})$ physical mixture and kneading the resultant mixture thoroughly with a pestle to obtain a homogeneous paste until the solvent was completely removed. The sample was dried at $40{ }^{\circ} \mathrm{C}$ in oven for $30 \mathrm{~min}$ to remove traces of solvent. The dried mass was pulverized.

\subsection{Fourier Transform Infrared (FT-IR) Spectroscopy}

FT-IR analysis was performed on Perkin Elmer Spectrum GX spectrometer (Waltham, MA, USA). FT-IR measurements of the pure materials (HPPA and $\beta$-CD), binary system and PM were carried out using the $\mathrm{KBr}$ disks method. The $\mathrm{KBr}$ disks were prepared by compressing the powder. The scanning range was kept from 4000 to $400 \mathrm{~cm}^{-1}$, with a resolution of $1 \mathrm{~cm}^{-1}$.

\subsection{Nuclear Magnetic Resonance (NMR) Spectroscopy}

NMR spectra of $\beta$-CD, HPPA and their kneading product HPPA: $\beta$-CD (KND) were carried out at $500 \mathrm{MHz}$ using a Varian UNITY 500 spectrometer. ${ }^{2} \mathrm{H}_{2} \mathrm{O}$ (99.9\% relative isotopic abundance) was purchased from Cambridge Isotope Laboratories. The proton chemical shifts were collected at $298 \mathrm{~K}$, at $\mathrm{pH}=5.8$, and referenced to external TMS $(\delta=0 \mathrm{ppm})$. Two-dimensional phase-sensitive TOCSY, NOESY, ROESY spectra [37] were collected using the States and Haberkorn method. Squared-shifted sine-bell functions were applied in both dimensions before Fourier transformation and baseline correction. TOCSY, NOESY and ROESY experiments were recorded with mixing times of 70, 200 and $150 \mathrm{~ms}$, respectively. Water suppression, when necessary, was achieved using the DPFGSE sequence [38]. The data were processed and analyzed using the VNMRJ and CARA software [39]. The 
proton chemical shifts for free HPPA (Figure 1) are summarized: $4.11 \mathrm{ppm}$ (proton in position 2a and 2a'), 3.28 ppm (2b and 2b'), 8.51 ppm (7), 9.11 ppm (4), 4.27 ppm (8a), 1.30 ppm (8b).

\subsection{Molecular Docking}

Docking was performed using the Hex software [40] version 6.3. The PDB files of CD and HPPA were uploaded as inputs into Hex and treated as receptor and ligand, respectively. All the input files were analyzed using the spherical harmonic surface of the Hex. Computations were performed by using the shape complementary scoring function, with 16 and 30 expansion orders for the initial and final search steps. The full list of parameters is given in the Table 2. Structure refinement and energy minimization were performed with Hex itself. Based on the energy minimization the best pose of the docked complex was selected.

Table 2. Hex parameters used in this study.

\begin{tabular}{lc}
\hline Correlation type & Shape only \\
\hline FFT Mode & 3D fast life \\
Receptor range angle & 180 \\
Ligand range angle & 180 \\
Twist range & 360 \\
Distance range & 40 \\
Docking main scan & 16 \\
Docking main search & 30 \\
\hline
\end{tabular}

\subsection{Ultraviolet-Visible (UV-Vis) Spectroscopy}

For all UV-Vis spectroscopy studies, a UV-1700 Spectrometer (Shimadzu, Tokyo, Japan) was used with $1 \mathrm{~cm}$ matched quartz cuvettes. All measurements were recorded in the wavelength range 200-400 $\mathrm{nm}$ at room temperature. The stoichiometry of the complex was determined using the continuous variation method [22,23]. According to this method, $0.05 \mathrm{mM}$ unbuffered solutions of HPPA and $\beta$-CD were mixed at different concentration ratios $R=[\beta-\mathrm{CD}] /([\mathrm{HPPA}]+[\beta-\mathrm{CD}])$ keeping the volume constant. The stoichiometric ratio was obtained by plotting $\Delta A \times R$ against $R$ (where $\Delta A$ is the difference of absorbance of HPPA without and with $\beta-C D$ ) and finding the $R$ value corresponding to the extreme of this dependence. The evaluation of $K_{\mathrm{b}}$ by direct spectroscopic methods relies on analytical differences between the free and complexed drug [24]. Changes in the absorption intensity of HPPA at $330 \mathrm{~nm}(\mathrm{pH}=6.8)$, at $323 \mathrm{~nm}(\mathrm{pH}=4.6)$, and at $331.5 \mathrm{~nm}(\mathrm{pH}=8.6)$, were monitored as a function of $\beta$-CD concentration to measure the $\mathrm{Kb}$. The HPPA concentration was kept constant $(0.05 \mathrm{mM})$ while $\beta$-CD concentration was varied $(0-1.85 \mathrm{mM})$. The absorbances of the resulting solutions were measured at different $\mathrm{pH}$ values obtained, adding proper buffer solutions. All absorption measurements were made against a blank solution treated the same way, but without HPPA and $\beta$-CD. Measurements of $\mathrm{pH}$ were performed using a calibrated CRISON pH-meter Basic 20. To conveniently calculate the $K_{\mathrm{b}}$, we needed to rearrange the Benesi-Hildebrand equation [25] into a straight line form [26] shown in the Equation (1). 


\section{Phase Solubility Studies}

Phase solubility studies were performed according to the method reported by Higuchi and Connors [27]. HPPA, in an amount (130.5 mg) that exceeded its solubility, was added into vials in which there were various concentrations of $\beta-C D(0-9 \mathrm{mM})$ and unbuffered MilliQ water $(5 \mathrm{~mL})$ at $\mathrm{pH}=6.8$, or buffered MilliQ water at $\mathrm{pH}=4.6$ or $\mathrm{pH}=8.6$. The vials were then sealed and thermostatically shaken at $40{ }^{\circ} \mathrm{C}$ for $100 \mathrm{~h}$. This amount of time is considered sufficient to reach equilibrium [10]. Subsequently, using a syringe the aliquots were filtered immediately through a $0.45 \mu \mathrm{m}$ Millipore membrane filter. A portion of the sample was analyzed by UV spectrophotometer at different $\lambda_{\max }: 323 \mathrm{~nm}(\mathrm{pH}=4.6) ; 330 \mathrm{~nm}(\mathrm{pH}=6.8) ; 331.5 \mathrm{~nm}(\mathrm{pH}=8.6)$. These wavelengths for the HPPA specific molar absorbance were obtained from the construction of calibration curves. The solubility experiments were performed in triplicate. The total concentration of HPPA solubilized was calculated as: $[\mathrm{HPPA}]=A_{\mathrm{HPPA}} / \varepsilon_{\mathrm{HPPA}}$ where $A_{\mathrm{HPPA}}$ is the phase solubility test absorbance and $\varepsilon_{\mathrm{HPPA}}$ is the specific molar absorbance of HPPA. It is implicitly assumed in the Higuchi and Connors [27] procedure that the EHPPA value does not change upon complexation with $\beta$-CD [41]. Phase Solubility Diagrams (PSD) were represented as the total dissolved drug concentration against the concentration of $\beta$-CD. The $\mathrm{Kb}$ for each complex was calculated from the slope of the straight-line portion curve, when PSD is $A_{\mathrm{L}}$ type according to the Equation 2 . The $\mathrm{Kb}$ for each complex, instead, was calculated from the rigorous nonlinear regression curve fitting [28] performed using Prism 5 software (GraphPad, San Diego, CA, USA), when PSD results Bs type.

\subsection{Bioactivity Evaluation}

\subsubsection{Microbial Susceptibility Test}

Two gram-negative bacteria and one gram-positive bacterium were tested in the Broth-based turbidometric assay. Among the former, P. aeruginosa and E. coli ATCC13762 were chosen. $P$. aeruginosa is a free-living bacterium commonly found in soil and water while $E$. coli is an opportunistic pathogen of clinical relevance for humans. The gram-positive bacterium utilized was the pathogen $S$. aureus ATCC6538. All bacteria were stored frozen in 90\% (v/v) glycerol in Tryptic Soy Broth (TSB, Oxoid) at $-80{ }^{\circ} \mathrm{C}$ until use when they were cultured in TSB overnight at $37{ }^{\circ} \mathrm{C}$. The test was performed using 96-well flat bottom micro-titre plates (Sarstedt, Italy) aseptically prepared. TSB broth aliquots $(100 \mu \mathrm{L})$ were poured into each well and $100 \mu \mathrm{L}$ of HPPA or of its complex were added to the top row and serial two-fold dilutions made by transferring $100 \mu \mathrm{L}$ each time to obtain the desired concentrations. The concentrations of HPPA were in the range from 0.013 to $3.376 \mathrm{mM}$, while in the complex, HPPA concentrations were from 0.003 up to $0.712 \mathrm{mM}$. Then, each well, except the TSB control (only medium) row, was inoculated with $100 \mu \mathrm{L}$ of the bacterial culture corresponding to $1 \times 10^{4} \mathrm{CFU}$ [42]. The final volume in each well was $200 \mu \mathrm{L}$. Before incubation at $37{ }^{\circ} \mathrm{C}$ for $20-24 \mathrm{~h}$, the plates were covered by a sterile film against evaporation. The optical density of each well at $620 \mathrm{~nm}$ was recorded using a microplate reader (Spectra Fluor, Tecan, Mannedorf, Switzeland). The results were compared to the control containing physiologic solution $(0.9 \% \mathrm{NaCl})$ in TSB and inoculum. Each experiment was performed in quadruplicate. While testing, a positive control was carried out with streptomycin at a starting concentration of $10 \mu \mathrm{g} / \mathrm{mL}$. The bacterial inhibition 
percentage was determined as follows: $100-\left(1-\mathrm{OD}_{620}\right.$ of test sample)/OD620 control bacterial growth $\times 100$. The effective concentrations inhibiting $50 \%\left(\mathrm{EC}_{50}\right)$ and $90 \%\left(\mathrm{EC}_{90}\right)$ of bacterial growth were determined.

\subsubsection{MTT-Assay}

The cell growth inhibition on human hepatocellular carcinoma (HepG2) and human breast adenocarcinoma (MCF-7) cell lines was determined by MTT assay, following the procedure of Mothanna et al. [43]. In this assay, the increase or decrease in the number of viable cells is linearly connected with the mitochondrial activity, highlighted by the conversion of the tetrazolium salt 3-(4,5-dimethylthiazol-2-yl)-2,5-diphenyltetrazolium bromide (MTT) into formazan crystals, which can be solubilized and spectrophotometrically quantified. The HPPA and HPPA: $\beta$-CD activity is expressed as the concentration of the compound able to achieve 50\% growth inhibition compared to the growth of the untreated control (50\% inhibitory concentration, $\mathrm{IC}_{50}$ ). The routine maintenance of HepG2 and MCF-7 cell lines consisted of their growth in Roswell Park Memorial Institute (RPMI) supplemented with 10\% fetal bovine serum (FBS), 2\% L-Glutamine, 2\% HEPES and $1 \%$ penicillin/streptomycin (10000 U/mL) (Lonza, Verviers, Belgium), at $37{ }^{\circ} \mathrm{C}$ in an atmosphere of $5 \%$ $\mathrm{CO}_{2}$ air under saturating humidity. In the MTT assay, HepG2 and MCF-7 cells were plated at $1 \times 10^{4}$ cells/well in a 96-well tissue culture plate and incubated for a sufficient time to assure attachment and $40 \%$ to $60 \%$ confluence. After $24 \mathrm{~h}$, the medium was aspirated off and replaced with fresh medium $(200 \mu \mathrm{L})$ containing the samples under investigation. HPPA concentration ranged from 0.05 to $1.65 \mathrm{mM}$, while in the complex, HPPA concentrations ranged from 0.01 to $0.35 \mathrm{mM}$. Three plates were incubated at $37{ }^{\circ} \mathrm{C}, 5 \% \mathrm{CO}_{2}$, for the OD measurements at 24,48 and $72 \mathrm{~h}$, respectively. After the respective incubation time, MTT solution $(20 \mu \mathrm{L})$ was added in each well, then incubated for a further $4 \mathrm{~h}$. After that, MTT-containing medium was gently removed and replaced with 2-propanol (200 $\mu \mathrm{L}$ per well). The plates were read at a microtitre plate reader at $590 \mathrm{~nm}$ (Spectrafluor, Tecan, Mannedorf, Switzeland). For each compound tested, the $\mathrm{IC}_{50}$ was calculated from the dose-response curves.

\subsubsection{Data Analysis}

HPPA and HPPA: $\beta-C D$ were examined three times (three independent assays) and results expressed as nominal concentrations. The results of MTT and turbidometric test were analyzed using Toxcalc $^{\text {TM }}$ (Tidepool Scientific Software, McKinleyville CA, USA, 1996). IC 50 values of the cell growth inhibition in HepG2 and MCF-7 cells as well as $\mathrm{EC}_{50}$ and $\mathrm{EC}_{90}$ values of bacterial growth were calculated by concentration/response regression using Maximum Likelihood-Logit method.

\section{Conclusions}

An inclusion complex of HPPA with $\beta$-CD (HPPA: $\beta-C D)$ was prepared in the solid state by kneading method and physical mixture. The formation of the inclusion complex was confirmed by FT-IR spectroscopy. In aqueous solution, the effect of $\beta$-CD on the absorption spectra of HPPA has been studied in buffered and unbuffered solutions at different $\mathrm{pH}$. The 1:1 stoichiometry was 
established by a Job plot and confirmed by phase solubility studies. The inclusion complex formation was investigated by UV-Vis titration and the HPPA: $\beta-C D$ stability constants $\left(K_{\mathrm{b}}\right)$, calculated for each $\mathrm{pH}$ value, resulted 215.2 $\mathrm{M}^{-1}$ at $\mathrm{pH}=4.6,79.7 \mathrm{M}^{-1}$ at $\mathrm{pH}=6.8$ and $90.7 \mathrm{M}^{-1}$ at $\mathrm{pH}=8.6$. The phase solubility studies, according to Higuchi and Connors method, were also performed at different $\mathrm{pH}$ values. The HPPA solubility is enhanced by the presence of the host in all the solutions. The PSD for HPPA: $\beta-\mathrm{CD}$ in buffer solutions at $\mathrm{pH}=4.6$ can be classified as Bs type and the $\mathrm{Kb}$ was estimated to be equal to $251.0 \mathrm{M}^{-1}$. The PSD for HPPA: $\beta-\mathrm{CD}$ in buffer solutions at $\mathrm{pH}=8.6$ and in unbuffered solution $(\mathrm{pH}=6.8)$, instead, can be classified as the $\mathrm{A}_{\mathrm{L}}$ type and, utilizing phase solubility diagrams data, the $K_{\mathrm{b}}$ were estimated to be equal to $88.5 \mathrm{M}^{-1}$ at $\mathrm{pH}=6.8$ and $87.0 \mathrm{M}^{-1}$ at $\mathrm{pH}=8.6$ respectively. The obtained inclusion complex was more stable under the acidic conditions due to the hydrophobic effect. NMR, docking and FT-IR of KND revealed that the less polar part of the molecule is inserted into the cavity, while the more polar groups are exposed to the bulk solvent. The biological activity of HPPA and its complex was determined to detect possible differences in their antibacterial capability. The results, expressed as $\mathrm{EC}_{50}$, showed that the complex exerted a robust action against $E$. coli and $S$. aureus. The calculation of $\mathrm{EC}_{90}$ values confirmed this result for $E$. coli in terms of HPPA amount reduction, demonstrating that the complex has the potential, after further investigation, to replace the use of HPPA in medicine. Furthermore, these compounds, tested on human breast adenocarcinoma MCF-7 cells and, for the first time to our knowledge, on the human hepatoblastoma HepG2 cell line, exhibited antitumor activity and the complex revealed a higher anticancer effect than HPPA, especially for HepG2 cells, opening interesting scenarios to explore. In conclusion, in this study we demonstrated an improvement of solubility of HPPA using $\beta$-CD. Moreover, the results indicate that the bioactivity of the drug remains in the HPPA: $\beta-C D$, indicating that $C D$ s may serve as excipient in pharmaceutical formulations. Further detailed studies, including the clarification of the structure-bioactivity relationship of the cyclodextrin inclusion complex by NMR analysis, are now in progress in our laboratories.

\section{Acknowledgments}

The authors are grateful to Maddalena Palmieri, Cristina Di Donato and Gennaro Aurino for useful discussion and Maurizio Muselli for excellent technical assistance. This work was partially funded by M.I.U.R. Grants PRIN 2009 (to C.I.).

\section{Conflict of Interest}

The authors declare no conflict of interest.

\section{References}

1. Matsumoto, J.; Minami, S. Pyrido[2,3-dipyrimidine antibacterial agents. 3,8-Alkyl-and 8-vinyl-5,8-dihydro-5-oxo-2-(1-piperazinyl)pyrido[2,3-d]-pyrimidine-6-carboxylic acids and their derivatives. J. Med. Chem. 1975, 18, 74-79.

2. Fonseca, I.; Martinex-Carrera, S.; Garcia-Blanco, S. Structure of pipemidic acid. Acta Crystallogr. Sect. C 1986, 42, 1618-1621. 
3. Toscano, M.A.; Serrao, A.; Ventimiglia, B.; Colosi, V.; Pennisi, M.; Morgana, R.; Bevilacqua, T. The use of pipemidic acid in urinary infections. Miner. Urol. 1982, 34, 257-260.

4. Hirai, K.; Ito, A.; Abe, Y.; Suzue, S.; Irikura, T.; Inoue, M.; Mitsuhashi, S. Comparative activities of AM-715 and pipemidic and nalidixic acids against experimentally induced systemic and urinary tract infections. Antimicrob. Agents Chemother. 1981, 19, 188-189.

5. Babić, S.; Horvat, A.J.M.; Pavlović, D.M.; Kaštelan-Macan, M. Determination of pKa values of active pharmaceutical ingredients. Trends Anal. Chem. 2007, 26, 1043-1061.

6. Shimizu, M.; Takase, Y.; Nakamura, S.; Katae, H.; Minami, A. Pipemidic acid: Its activities against various experimental infections. Antimicrob. Agents Chemother. 1976, 9, 569-574.

7. Zweerink, M.M.; Edison, A. Inhibition of micrococcus luteus DNA gyrase by norfloxacin and 10 other quinolone carboxylic acids. Antimicrob. Agents Chemother. 1986, 29, 598-601.

8. Efthimiadou, E.K.; Sanakis, Y.; Katsaros, N.; Karaliota, A.; Psomas, G. Transition metal complexes with the quinolone antibacterial agent pipemidic acid: Synthesis, characterization and biological activity. Polyhedron 2007, 26, 1148-1158.

9. Zhang, C.L.; Wang, Y. Aqueous solubilities for ofloxacin, norfloxacin, lomefloxacin, ciprofloxacin, pefloxacin, and pipemidic acid from (293.15 to 323.15) K. J. Chem. Eng. Data 2008, 53, 1295-1297.

10. Romero, S.; Bustamante, P.; Escalera, B.; Mura, P.; Cirri, M. Influence of solvent composition on the solid phase at equilibrium with saturated solutions of quinolones in different solvent mixtures. J. Pharm. Biomed. Anal. 2004, 35, 715-726.

11. Szejtli, J. Cyclodextrin Technology; Kluwer Academic: Dordecht, The Netherlands, 1989; pp. 8-72.

12. Duchene, D.; Vaution, C.; Glomot, F. Cyclodextrin, their value in pharmaceutical technology. Drug Dev. Ind. Pharm. 1988, 12, 2193-2215.

13. Singh, R.; Bharti, N.; Madan, J.; Hiremath, S.N. Characterization of cyclodextrin inclusion complexes-A review. J. Pharm. Sci. Technol. 2010, 2, 171-183.

14. Pires, M.A.S.; dos Santos, R.A.S.; Sinisterra, R.D. Pharmaceutical composition of hydrochlorothiazide: $\beta$-cyclodextrin: Preparation by three different methods, physico-chemical characterization and in vivo diuretic activity evaluation. Molecules 2011, 16, 4482-4499.

15. Wang, S.W.; Pan, S.L.; Huang, Y.C.; Guh, J.H.; Chiang, P.C.; Huang, D.Y.; Kuo, S.C.; Lee, K.H.; Teng, C.M. CHM-1, a novel synthetic quinolone with potent and selective antimitotic antitumor activity against human hepatocellular carcinoma in vitro and in vivo. Mol. Cancer Ther. 2008, 7, 350-359.

16. Chen, Y.C.; Lu, P.H.; Pan, S.L.; Teng, C.M.; Kuo, S.C.; Lin, T.P.; Ho, Y.F.; Huang, Y.C.; Guh, J.H. Quinolone analogue inhibits tubulin polymerization and induces apoptosis via Cdk1-involved signaling pathways. Biochem. Pharmacol. 2007, 74, 10-19.

17. Menezes, P.P.; Serafini, M.R.; Santana, B.V.; Nunes, R.S.; Quintans, L.J., Jr.; Silva, G.F.; Medeiros, I.A.; Marchioro, M.; Fraga, B.P.; Santos, M.R.V.; et al. Solid-state $\beta$-cyclodextrin complexes containing geraniol. Thermochim. Acta 2012, 548, 45-50.

18. Sahoo, S.; Chakraborti, C.K.; Behera, P.K. FTIR and Raman spectroscopic investigations of a controlled release Ciprofloxacin/Carbopo1940 mucoadhesive suspension. Asian J. Pharm. Clin. Res. 2012, 5, 125-130. 
19. Aithal, K.S.; Udupa N. Physicochemical study of ciprofloxacin with $\beta$-cyclodextrin. Pharm. Sci. 1996, 2, 451-455.

20. Li, J.; Zhao, C.; Chao, J. Investigation on the inclusion behavior of Norfloxacin with 2-methyl- $\beta$-cyclodextrin. J. Inclusion Phenom. Macrocyclic Chem. 2008, 62, 325-331.

21. Rawat, S.; Jain, S.K. Solubility enhancement of celecoxib using $\beta$-cyclodextrin inclusion complexes. Eur. J. Pharm. Biopharm. 2004, 57, 263-267.

22. Job, P. Formation and stability of inorganic complexes in solution. Annal. Chim. Fr. 1928, 9, 113-203.

23. Huang, C.Y. Determination of binding stoichiometry by the continuous variation method: The Job plot. Methods Enzymol. 1982, 87, 509-525.

24. Connors, K.A. The stability of cyclodextrin complexes in solution. Chem. Rev. 1997, 97, 1325-1357.

25. Benesi, H.A.; Hildebrand, J.H. A spectrophotometric investigation of the interaction of iodine with aromatic hydrocarbons. J. Am. Chem. Soc. 1949, 71, 2703-2707.

26. Iacovino, R.; Caso, J.V.; Rapuano, F.; Russo, A.; Isidori, M.; Lavorgna, M.; Malgieri, G.; Isernia, C. Physicochemical characterization and cytotoxic activity evaluation of hydroxymethylferrocene: $\beta$-Cyclodextrin inclusion complex. Molecules 2012, 17, 6056-6070.

27. Higuchi, T.; Connors, K.A. Phase solubility techniques. Anal. Chem. Instrum. 1965, 4, 117-212.

28. Zughul, M.B. Rigorous nonlinear regression analysis of phase solubility diagrams to obtain complex stoichiometry and true thermodynamic drug-cyclodextrin complexation parameters. J. Incl. Phenom. Macrocyclic Chem. 2007, 57, 525-530.

29. Loftsson, T.; Brewster, M.E. Pharmaceutical applications of cyclodextrins: Effects on drug permeation through biological membranes. J. Pharm. Pharmacol. 2011, 63, 1119-1135.

30. Durán-Merás, I.; Muñoz De La Peña, A.; Salinas López, F.; Rodríguez Cáceres, M.I. Complexation study and spectrofluorimetric determination of pipemidic acid with $\gamma$-cyclodextrin. J. Incl. Phenom. Macrocycl. Chem. 2005, 51, 137-142.

31. Shimizu, M.; Takase, Y.; Nakamura, S.; Katae, H.; Minami, A.; Nakata, K.; Inoue, S.; Ishiyama M.; Kubo, Y. Pipemidic acid, a new antibacterial agent active against pseudomonas aeruginosa: In vitro properties. Antimicrob. Agents Chemother. 1975, 8, 132-138.

32. Chin, N.; Neu, H.C. Ciprofloxacin, a quinolone carboxylic acid compound active against aerobic and anaerobic bacteria. Antimicrob. Agents Chemother. 1984, 25, 319-326.

33. Wada, K.; Kariyama, R.; Mitsuhata, R.; Uehara, S.; Watanabe, T.; Monden, K.; Kumon, H. Experimental and clinical studies on fluoroquinolone-insusceptible Escherichia coli isolated from patients with urinary tract infections from 1994 to 2007. Acta Med. Okayama 2009, 63, 263-272.

34. Yang, L.; Tao, D.; Yang, X.; Li, Y.; Guo, Y. Synthesis, characterization, and antibacterial activities of some rare earth metal complexes of Pipemidic Acid. Chem. Pharm. Bull. 2003, 51, 494-498.

35. Sha, J.Q.; Liang, L.Y.; Li, X.M.; Zhang, Y.; Yan, H.; Chen, G. Ligation of the quinolone antibacterial agent pipemidic acid to Keggin polyoxotungstates. Polyhedron 2011, 30, 1657-1662.

36. Sha, J.Q.; Liang, L.Y.; Yan, P.F.; Li, G.M.; Wanga, C.; Mab, D.Y. Study on ligation of copper complexes of the quinolone antibacterial drugs and octamolybdates POMs. Polyhedron 2012, 31, 422-430. 
37. Cavanagh, J.; Fairbrother, W.; Palmer, A.G.; Skelton N.J. Protein NMR Spectroscopy, Principles, and Practice; Academic Press, Inc.: San Diego, CA, USA, 1996.

38. Hwang, T.L.; Shaka, A.J. Water suppression that works. Excitation sculpting using arbitrary wave-forms and pulsed-field gradients. J. Magn. Reson. A 1995, 112, 275-279.

39. Bartels, C.; Xia, T.; Billeter, M.; Gunter, P.; Wüthrich, K.J. The program XEASY for computer-supported NMR spectral analysis of biological macromolecules. J. Biomol. NMR 1995, $6,1$.

40. Ritchie, D.W.; Venkatraman, V. Ultra-fast FFT protein docking on graphics processors. Bioinformatics 2010, 26, 2398-2405.

41. Moriwaki, C.; Costa, G.L.; Ferracini, C.N.; de Moraes, F.F.; Zanin, G.M.; Pineda, E.A.G.; Matioli G. Enhancement of solubility of albendazole by complexation with $\beta$-Cyclodextrin. Braz. J. Chem. Eng. 2008, 25, 255-267.

42. Othman, M.; San Loh, H.; Wiart, C.; Khoo, T.J.; Hon Lim, K.; Nee Ting, K. Optimal methods for evaluating antimicrobial activities from plant extracts. J. Microbiol. Methods 2011, 84, 161-166.

43. Mothanna, A.; Rosli, R.; Swee-Keong, Y.; Abdul-Rahman, O.; Abdul-Manaf, A.; Noorjahan, B.A. Selective Cytotoxicity of goniothalamin against hepatoblastoma HepG2 cells. Molecules 2011, 16, 2944-2959.

(C) 2013 by the authors; licensee MDPI, Basel, Switzerland. This article is an open access article distributed under the terms and conditions of the Creative Commons Attribution license (http://creativecommons.org/licenses/by/3.0/). 